\title{
General Psychiatry Literature review and economic evaluation of oral and intramuscular ziprasidone treatment among patients with schizophrenia in China
}

\author{
Yu-Chen Yeh, ${ }^{1}$ Xin $Y u,{ }^{2}$ Congpei Zhang, ${ }^{3}$ Wei Hao, ${ }^{4}$ Fen Du, ${ }^{5}$ Dongdong Liu, ${ }^{6}$ \\ Lili Yang, ${ }^{6}$ Xin $\mathrm{Gao}^{7}$
}

To cite: Yeh Y-C, Yu X, Zhang C, et al. Literature review and economic evaluation of oral and intramuscular ziprasidone treatment among patients with schizophrenia in China. General Psychiatry 2019;31:e100016. doi:10.1136/ gpsych-2018-100016

Received 19 September 2018 Revised 13 November 2018 Accepted 15 November 2018

Check for updates

(c) Author(s) (or their employer(s)) 2019. Re-use permitted under CC BY-NC. No commercial re-use. See rights and permissions. Published by BMJ.

${ }^{1}$ Pharmerit International, Newton, Massachusetts, USA ${ }^{2}$ Psychiatry Department, Institute of Mental Health, Peking University, Beijing, China ${ }^{3}$ Psychiatry Department, The First Specialized Hospital of Harbin, Harbin, China

${ }^{4}$ Mental Health Institute, Second

Xiangya Hospital of Central

South University, Hunan, China

${ }^{5}$ Pharmerit (Shanghai) Company

Limited, Shanghai, China

${ }^{6}$ Pfizer Investment Co., Ltd,

Beijing, China

${ }^{7}$ Pharmerit International, Bethesda, Maryland, USA

Correspondence to

Yu-Chen Yeh;

yyeh@pharmerit.com

\section{ABSTRACT}

Background Over 10 million Chinese are affected by schizophrenia. The annual cost of schizophrenia in China was estimated at US\$2586 per patient.

Aims The study has two aims: (1) to conduct a targeted literature review of the economic literature on oral ziprasidone in China, and (2) to develop an inpatient economic model that compared the cost of intramuscular ziprasidone with other regimens including electroconvulsive therapy (ECT) for the management of acute agitation in patients with schizophrenia from a hospital's perspective in China.

Methods A targeted literature review was conducted using PubMed and the Chinese literature databases for studies published between January 2007 and December 2017. Studies that assessed costs associated with oral ziprasidone treatment for schizophrenia in China were summarised. In the inpatient economic model, cost measures included hospital room and board, antipsychotics, ECT and medications for the management of extrapyramidal symptoms (EPS). Input for standard antipsychotic regimens and unit cost were obtained from the literature. Hospital length of stay (LOS), utilisation of ECT and incidence of EPS were derived from the literature and supplemented/validated with a survey of psychiatrists in China. Cost was presented in 2017 Chinese yuan.

Results The average estimated LOS was 29 days with ziprasidone, 33 days with risperidone+benzodiazepine, 32 days with olanzapine, 35 days with haloperidol and 29 days with ECT. The cost of antipsychotics was $¥ 1260$ with ziprasidone, $¥ 137$ with risperidone+benzodiazepine, $¥ 913$ with olanzapine and $¥ 210$ with haloperidol; ECT treatment cost $¥ 785$. The base-case analysis suggested that higher antipsychotic cost with ziprasidone was offset by savings with shorter LOS. Using intramuscular ziprasidone for acute management was associated with a total cost of $¥ 11$ 157 , the lowest among all antipsychotic regimens ( $¥ 11424$ with risperidone+benzodiazepine, $¥ 11711$ with olanzapine and $¥ 11912$ with haloperidol) and slightly higher than ECT (¥10 606). The cost of antipsychotics and ECT accounted for $1 \%-11 \%$ of the total cost. Varying LOS between the lower and upper bounds of the $95 \% \mathrm{Cl}$, the total cost was comparable between these regimens.

Conclusions Overall, the cost for the management of acute agitation was similar between intramuscular ziprasidone and other antipsychotics. Compared with other antipsychotics, the higher medication cost of intramuscular ziprasidone can be offset by savings with shorter hospital stay. The results from this economic analysis were complementary to the findings in the published literature assessing the economic outcomes of oral ziprasidone.

\section{INTRODUCTION}

Schizophrenia is a disabling and chronic psychiatric disorder with an estimated worldwide prevalence of $0.30 \%-0.66 \%{ }^{1}$ In China, an estimated $0.78 \%$ of the population is affected by schizophrenia, equating to over 10 million people. ${ }^{2}$ Schizophrenia causes a substantial economic burden on patients, families, caregivers and the society as a whole. ${ }^{3}$ The economic cost of schizophrenia in China was estimated at US\$2586 per patient per year; indirect costs due to productivity losses incurred by patients and caregivers accounted for two-thirds of the cost. ${ }^{4}$

Treatment for schizophrenia can be characterised into three phases: acute treatment, stabilisation and stable. In the acute treatment phase, the goals are to prevent harm, minimise destructive behaviour, and manage agitation and aggression. Rapid initiation of antipsychotic treatment is recommended to control symptoms. In the stabilisation phase, the goals are to reduce the risk of relapse and facilitate integration into the community and patient recovery. During this phase, patients should remain on pharmacotherapy and be monitored for adverse events. In the stable phase, continued use of antipsychotic agents is strongly recommended as it reduces the risk of relapse and increases the likelihood of sustained control. ${ }^{56}$

Antipsychotics for the treatment of schizophrenia can be categorised as typical (first-generation) or atypical (second-generation). Although these two types of antipsychotics have similar efficacy, their side effects and tolerability profiles are different. ${ }^{7}$ Antipsychotic choice should be individualised, based on the 
patient's previous experience with side effects and symptom response, presence of comorbid conditions, preferred route of administration and potential interaction with concomitant medications. ${ }^{5}$

Atypical antipsychotics, in general, are associated with a lower risk of extrapyramidal symptoms (EPS) compared with typical antipsychotics; however, adverse effects, such as weight gain, metabolic syndrome, hyperprolactinaemia and somnolence, are more common. ${ }^{8}$ Weight gain and metabolic syndrome are important factors for consideration in the long-term treatment of schizophrenia as these adverse effects negatively affect patients' physical health, quality of life and satisfaction. ${ }^{910}$ Results from a recent network meta-analysis of atypical antipsychotic use in Chinese patients with schizophrenia suggest that aripiprazole, amisulpride and ziprasidone have less effect on weight gain and olanzapine has more effect than other agents. ${ }^{11}$

Antipsychotic agents are available in several formulations, including oral, short-acting intramuscular injections and long-acting intramuscular injections. For the management of acute agitation, the Chinese guidelines for schizophrenia recommend the use of an intramuscular injection of haloperidol or ziprasidone, or oral administration of an atypical antipsychotic combined with a benzodiazepine, as first-line therapy. ${ }^{6}$ After the patient's acute agitation is controlled, they should be switched from intramuscular to oral therapy or continue the oral atypical antipsychotic. In patients who fail first-line therapy for acute agitation, clozapine or combination therapy with an antipsychotic and a mood stabiliser is recommended. Modified electroconvulsive therapy (ECT) can be considered in patients who do not respond to, or who cannot tolerate, antipsychotic therapy.

In China, ziprasidone is the only atypical antipsychotic that is available as a short-acting intramuscular formulation. The advantage of intramuscular injections versus oral administration is the rapid onset of action and the ability to administer medications to patients who are not cooperative. ${ }^{12}$ In a randomised controlled study enrolling Chinese patients with schizophrenia, intramuscular ziprasidone had similar efficacy but a reduced risk of EPS (2.1\% vs $36.9 \%$, $p=$ not reported) compared with intramuscular haloperidol. ${ }^{13}$ Differences in EPS risk may affect other healthcare resource use and hospital length of stay.

The availability of both short-acting intramuscular and oral formulations of ziprasidone allows patients to stay on the same medication as they transition from initial management with intramuscular injection to subsequent oral therapy. ${ }^{14}$ This is of particular benefit for patients who are not suitable for long-term treatment with other atypical antipsychotic due to the risk of EPS, weight gain and metabolic complications. While intramuscular ziprasidone is recommended as the first-line therapy for acute agitation, ${ }^{6}$ there are concerns about the relatively high cost of ziprasidone compared with intramuscular haloperidol and other oral atypical antipsychotics to hospitals. To understand the overall economic outcomes of intramuscular ziprasidone for the hospital, both the costs of the antipsychotics and the costs of other healthcare resources should be considered.
Furthermore, although modified ECT is recommended only for treatment-resistant patients in the Chinese guideline ${ }^{6}$ it is commonly used in clinical practice as a first-line therapy in place of antipsychotics because hospitals are pressured to reduce the ratio of pharmacy to total costs. Currently, there are no published studies that assess the overall economic impact of intramuscular ziprasidone and other regimens for the management of acute agitation in patients with schizophrenia from the hospital's perspective in China.

Since patients who receive intramuscular ziprasidone will likely transition to oral ziprasidone, the objective of the study was to assess the economic impact of ziprasidone, including intramuscular and oral forms, in the acute and long-term treatment phase of Chinese patients with schizophrenia. The study consisted of two parts: (1) a targeted literature review of the economic literature on oral ziprasidone in China, and (2) a cost comparison of intramuscular ziprasidone with other regimens including ECT for the management of acute agitation in patients with schizophrenia from a hospital's perspective in China.

\section{METHODS}

\section{Literature review}

A targeted literature review was conducted using PubMed and two Chinese literature databases, Wanfang and the China National Knowledge Infrastructure (CNKI), for studies published between January 2007 and December 2017. Keywords included ziprasidone (齐拉西酮), schizophrenia (精神分裂症), cost (成本), economic (经济学) and resource (资源). Studies in English or Chinese that assessed costs associated with oral ziprasidone treatment for schizophrenia in China were reviewed and summarised.

\section{Cost comparison of intramuscular ziprasidone for acute management in inpatient setting}

This cost-analysis model compared the cost associated with intramuscular ziprasidone, intramuscular haloperidol, oral olanzapine, oral risperidone plus oral benzodiazepine, and ECT during a hospital stay for the management of acute agitation in patients with schizophrenia. These regimens were selected because they are commonly used to treat Chinese patients with schizophrenia in clinical practice. Patients who initiated intramuscular antipsychotic therapy were transitioned to an oral regimen of the same agent after a few days. The model was developed from a hospital perspective and included the cost of antipsychotics, drug administration, ECT and relevant monitoring procedures, hospital room and board, and medications for the management of EPS. It was assumed that patients in the ECT group received an ECG, electroencephalogram and CT of the brain. Costs are presented in 2017 Chinese yuan ( $¥ 1=\mathrm{US} \$ 0.15$ ). The model was structured in Microsoft Excel.

The antipsychotic regimens were based on the guideline recommendations $^{6}$ (table 1). Due to the lack of information in the literature, the length of hospital stay for each 
Table 1 Comparison of antipsychotic standard regimen and ECT

\begin{tabular}{|c|c|c|c|}
\hline Initial treatment & Regimen $^{6}$ & EPS, mean \% (range)* & $\begin{array}{l}\text { Hospital length of stay, mean } \\
\text { days }(95 \% \mathrm{Cl})^{*}\end{array}$ \\
\hline Intramuscular ziprasidone & $\begin{array}{l}\text { Intramuscular injection } 10-20 \\
\text { mg, up to } 40 \text { mg per day for } \\
3 \text { days, then oral } 80 \text { mg twice } \\
\text { daily }\end{array}$ & $7(0-30)$ & 29.33 (23.44 to 35.22$)$ \\
\hline Intramuscular haloperidol & $\begin{array}{l}\text { Intramuscular } 2-5 \text { mg every } \\
4-8 \text { hours for } 3-7 \text { days, then } \\
\text { oral } 5-10 \text { mg per day }\end{array}$ & $43(8-80)$ & 34.67 (29.52 to 39.82$)$ \\
\hline Oral olanzapine & Oral 20 mg per day & $14(1-20)$ & 32.00 (25.12 to 38.88$)$ \\
\hline $\begin{array}{l}\text { Oral risperidone and oral } \\
\text { benzodiazepine }\end{array}$ & $\begin{array}{l}\text { Oral risperidone } 2 \mathrm{mg} \text { twice } \\
\text { daily and oral lorazepam } 1 \mathrm{mg} \\
\text { twice daily }\end{array}$ & $26(6-50)$ & 33.44 (25.52 to 41.36$)$ \\
\hline ECT & $\begin{array}{l}6.67 \text { times during hospital } \\
\text { stay }\end{array}$ & NA & 29.11 (23.15 to 35.07 ) \\
\hline
\end{tabular}

*Based on physician survey.

ECT, electroconvulsive therapy; EPS, extrapyramidal symptoms; NA, not applicable.

regimen and the frequency of ECT were obtained from a survey of nine physicians with expertise in treating patients with schizophrenia. Simple average of the estimates provided by the nine physicians was calculated and used in the base-case analysis (table 1). In addition, information on antipsychotic regimens used in their hospitals, rates of EPS for each regimen based on their experience and therapies for EPS was collected (table 1). Physicians participating in the survey had an average of 23 years of experience in treating patients with schizophrenia. Trihexyphenidyl (oral 2-5 mg three times per day), alprazolam (oral $0.4 \mathrm{mg}$ twice per day), propranolol (oral 30-60 mg per day) and lorazepam (oral 0.5-2 mg per day) were commonly used for the management of EPS.

The unit cost of drugs was based on the price listed on the Integrated Management Platform website of Beijing Medicine Sunshine Purchase (IMPBMSP), ${ }^{15}$ a compositor of prices submitted by pharmaceutical companies for hospitals in Beijing. Another online source was used ${ }^{16}$ if information was not available on IMPBMSP. The average purchase price was calculated for each agent. If generics were available, the average price for the generic formulation was used. The cost of intramuscular administration, ECT and relevant monitoring tests was obtained from the Beijing Development and Reform Commission. ${ }^{17}$ The cost per hospital day in a psychiatric unit was estimated based on data from the literature and inflated to 2017 $\operatorname{costs}^{18}$ (table 2).

One-way sensitivity analyses were conducted to assess the effect of uncertainty in model parameters. The results were tested by changing the hospital length of stay based on the $95 \%$ CI of the estimates provided by the physicians. In addition, EPS rates for intramuscular ziprasidone (2\%) and intramuscular haloperidol (37\%) reported in the study by Zhang ${ }^{13}$ and colleagues were used in the sensitivity analysis.

\section{RESULTS}

\section{Literature review}

A total of 222 articles were identified in the search; 161 from PubMed and 61 from Chinese databases. Based on title and abstract review, 12 articles (all from the Chinese databases) were considered relevant and were summarised. Ten of the 12 studies evaluated the

\begin{tabular}{|lc|}
\hline \multicolumn{2}{|l|}{ Table 2 Summary of cost inputs } \\
\hline Variable & \multicolumn{2}{l}{ Mean value, $¥$} \\
\hline Medications (cost per mg) \\
\hline \multicolumn{1}{l|}{ Intramuscular ziprasidone } & 8.14 \\
\hline Oral ziprasidone & 0.12 \\
\hline Intramuscular haloperidol & 0.90 \\
\hline Oral haloperidol & 0.14 \\
\hline Oral olanzapine & 1.43 \\
\hline Oral risperidone & 0.96 \\
\hline Oral lorazepam & 0.13 \\
\hline Oral trihexyphenidyl & 0.08 \\
\hline Oral alprazolam & 0.61 \\
\hline Oral propranolol & 0.01 \\
\hline Drug administration & \\
\hline Intramuscular injection & 4.50 \\
\hline Procedure & \\
\hline Electroconvulsive therapy & 90 \\
\hline ECG & 10 \\
\hline Electroencephalogram & 40 \\
\hline CT of the brain & 135 \\
\hline Hospitalisation & 337 \\
\hline poom and board in & \\
\hline
\end{tabular}


Table 3 Summary of economic outcomes of oral ziprasidone over 4-8 weeks

Study design, cost

year Duration Results

\begin{tabular}{llll}
\hline Outpatient & & & \\
Changchun $\mathrm{He}^{21}$ & $\mathrm{RCT}(\mathrm{n}=84)$ & 6 weeks & $\begin{array}{l}\text { Oral ziprasidone: } ¥ 1624 . \\
\text { Oral quetiapine: } ¥ 2534 . \\
\end{array}$ \\
2011 & & No difference in effectiveness.
\end{tabular}

\begin{tabular}{|c|c|c|c|}
\hline Shangxiong $\mathrm{Hao}^{22}$ & $\begin{array}{l}\text { RCT }(n=88) \\
2013\end{array}$ & 6 weeks & $\begin{array}{l}\text { Oral ziprasidone: } ¥ 504 \text {. } \\
\text { Oral risperidone: } ¥ 420 \text {. } \\
\text { No difference in effectiveness. }\end{array}$ \\
\hline Biao $\mathrm{Du}^{20}$ & $\begin{array}{l}\text { CEA based on data } \\
\text { from RCTs } \\
2009\end{array}$ & 8 weeks & $\begin{array}{l}\text { Oral ziprasidone: } ¥ 808 \text {. } \\
\text { Oral risperidone: } ¥ 694 \text {. } \\
\text { No difference in effectiveness. }\end{array}$ \\
\hline Hongli Shuai ${ }^{23}$ & $\begin{array}{l}\text { CEA based on data } \\
\text { from } 1 \text { RCT }(n=120) \\
2007\end{array}$ & 6 weeks & $\begin{array}{l}\text { Oral ziprasidone: } ¥ 602 \text {. } \\
\text { Oral risperidone: } ¥ 608 \text {. } \\
\text { No difference in effectiveness. }\end{array}$ \\
\hline Xin Guan ${ }^{19}$ & $\begin{array}{l}\text { CEA based on meta- } \\
\text { analysis } \\
2016\end{array}$ & 8 weeks & $\begin{array}{l}\text { Oral ziprasidone: } ¥ 832 \text {. } \\
\text { Oral risperidone: } ¥ 235 \text {. } \\
\text { Oral olanzapine: } ¥ 1310 \text {. } \\
\text { Oral quetiapine: } ¥ 369 \text {. } \\
\text { Oral aripiprazole: } ¥ 553 \text {. } \\
\text { Oral risperidone dominant vs oral quetiapine, aripiprazole and olanzapine. } \\
\text { Oral ziprasidone is more expensive but more effective. } \\
\text { The incremental cost per treatment response achieved with ziprasidone } \\
\text { was } ¥ 25194 \text { (2016 cost) compared with risperidone over } 8 \text { weeks (\% } \\
\text { achieved treatment response: } 87.06 \% \text { vs } 84.69 \% \text {; drug cost: } ¥ 831.60 \text { vs } \\
¥ 234.50 \text { ). }\end{array}$ \\
\hline Junfang Duan ${ }^{24}$ & $\begin{array}{l}\text { RCT }(n=126) \\
2013\end{array}$ & 6 weeks & $\begin{array}{l}\text { Oral ziprasidone: } ¥ 510 \text {. } \\
\text { Oral risperidone: } ¥ 428 \text {. } \\
\text { No difference in effectiveness. }\end{array}$ \\
\hline
\end{tabular}

Inpatient

\begin{tabular}{|c|c|c|c|}
\hline Yuqin Wang ${ }^{25}$ & $\begin{array}{l}\mathrm{RCT}(\mathrm{n}=138) \\
2013\end{array}$ & 30 days & $\begin{array}{l}\text { Oral ziprasidone: } ¥ 530 \text {. } \\
\text { Oral risperidone: } ¥ 224 \text {. } \\
\text { Oral olanzapine: } ¥ 1005 \text {. } \\
\text { No difference in effectiveness. }\end{array}$ \\
\hline Qionghua Liu' & $\begin{array}{l}\text { RCT }(n=160) \\
2009\end{array}$ & $\begin{array}{l}\text { Not } \\
\text { reported }\end{array}$ & $\begin{array}{l}\text { Oral ziprasidone: } ¥ 1891 \text {. } \\
\text { Oral risperidone: } ¥ 668 \text {. } \\
\text { Oral olanzapine: } ¥ 2426 \text {. } \\
\text { Oral quetiapine: } ¥ 7974 \text {. } \\
\text { No difference in effectiveness. }\end{array}$ \\
\hline Ruicheng Wang ${ }^{27}$ & $\begin{array}{l}\text { RCT }(n=179) \\
2009\end{array}$ & $\begin{array}{l}\text { Not } \\
\text { reported }\end{array}$ & $\begin{array}{l}\text { Oral ziprasidone: } ¥ 1836 \text {. } \\
\text { Oral risperidone: } ¥ 642 \text {. } \\
\text { Oral olanzapine: } ¥ 2236 \text {. } \\
\text { Oral quetiapine: } ¥ 7434 \text {. } \\
\text { No difference in effectiveness. }\end{array}$ \\
\hline Chaowei Wei ${ }^{28}$ & $\begin{array}{l}\text { RCT }(n=96) \\
2010\end{array}$ & 8 weeks & $\begin{array}{l}\text { Oral ziprasidone: } ¥ 3064 \text {. } \\
\text { Oral risperidone: } ¥ 1248 \text {. }\end{array}$ \\
\hline
\end{tabular}

CEA, cost-effectiveness analysis; RCT, randomised controlled trial.

economic outcomes of oral ziprasidone in the short term (ie, over 4-8 weeks) and 2 studies evaluated the costs for oral ziprasidone in the long term (ie, 1 or 2 years).

\section{Economic outcomes of oral ziprasidone over 4-8 weeks}

Previous studies compared the cost and effectiveness of oral ziprasidone with oral risperidone oral olanzapine oral quetiapine and oral aripiprazole (table 3). Most of the studies were based on a single clinical trial; two studies used data from multiple clinical trials. ${ }^{19}{ }^{20}$ Six of the 10 studies were conducted in the outpatient setting. ${ }^{19-24}$
Study results consistently showed that oral ziprasidone was more costly than oral risperidone ${ }^{19} 2022$ 24-28 but less expensive than oral olanzapine, ${ }^{1925-27}$ oral quetiapine ${ }^{212627}$ None of the studies reported a statistically significant difference in efficacy among the drugs. However, a more favourable tolerability profile and numerically higher treatment response rate, in general, were reported for oral ziprasidone compared with oral risperidone. ${ }^{192} 202-25$ The results from a study conducted in 2016 using efficacy data from a meta-analysis show that the incremental cost 


\begin{tabular}{lccccc}
\hline \multicolumn{7}{c}{ Table 4} & Total cost of base-case analysis, 2017 Chinese yuan (\% out of total cost) & & \\
& $\begin{array}{l}\text { Intramuscular } \\
\text { ziprasidone }\end{array}$ & $\begin{array}{l}\text { Intramuscular } \\
\text { haloperidol }\end{array}$ & Oral olanzapine & $\begin{array}{l}\text { Oral risperidone } \\
\text { plus lorazepam }\end{array}$ & ECT \\
\hline Hospital room and board & $9896(88.7)$ & $11696(98.2)$ & $10796(92.2)$ & $11283(98.8)$ & $9821(92.6)$ \\
Antipsychotics/procedure & $1260(11.3)$ & $210(1.8)$ & $913(7.8)$ & $137(1.2)$ & $785(7.4)$ \\
Management of EPS & $1(<1)$ & $6(<1)$ & $2(<1)$ & $3(<1)$ & - \\
Total & 11157 & 11912 & 11711 & 11424 & 10606
\end{tabular}

ECT, electroconvulsive therapy; EPS, extrapyramidal syndrome.

per treatment response achieved with oral ziprasidone compared with oral risperidone was $¥ 25194$ (2016 cost) over 8 weeks (\% achieved treatment response: $87.06 \%$ vs $84.69 \%$; drug cost: $¥ 831.60$ vs $¥ 234.50) .{ }^{19}$

\section{Economic outcomes of long-term treatment with oral ziprasidone}

Two studies reported the long-term clinical and economic outcomes of oral ziprasidone compared with other orally administered atypical antipsychotics. In one study, patients who received oral atypical antipsychotics therapy in the inpatient setting were followed for 1 year after discharge. ${ }^{29}$ Whether patients with treatment-resistant symptoms were included in the study was not specified. Direct (medical, travel for medical care) and indirect (productivity loss) costs were evaluated. The total costs were lowest for oral clozapine (¥4842), followed by oral risperidone (¥7965). The total costs were similar for oral ziprasidone (¥16 871) and oral aripiprazole (¥15 324), which were lower than oral quetiapine ( $¥ 20675$ ) and oral olanzapine (¥22 647). ${ }^{29}$ Oral clozapine had the lowest response rate $(79.59 \%)$, whereas oral ziprasidone and oral aripiprazole had the highest response rates $(89.80 \%)$; the difference was not statistically different between any of these agents. Compared with oral clozapine, the incremental cost per treatment response achieved was $\$ 1178$ with oral ziprasidone and $\$ 1027$ with oral aripiprazole. Compared with oral risperidone (response rate $=87.76 \%$ ), the incremental cost per treatment response achieved was $\$ 4366$ with oral ziprasidone and $\$ 3607$ with oral aripiprazole.

The other study compared the cost of oral ziprasidone and oral clozapine over 2 years among patients who had treatment-resistant symptoms and who were admitted to the hospital for acute schizophrenia management. While oral ziprasidone was associated with higher direct medical costs (¥297000), the total costs were lower compared with oral clozapine as patients receiving oral ziprasidone had less productivity losses. ${ }^{30}$ The results of this 2-year study were different from the results in the above-mentioned 1-year study where the total cost was lower with oral clozapine compared with ziprasidone. ${ }^{29}$ The main factor for the difference was productivity losses. Lower productivity loss with ziprasidone compared with clozapine was able to offset the higher cost of ziprasidone in the 2-year study ${ }^{30}$ but not in the 1-year study. ${ }^{29}$

\section{Cost comparison of intramuscular ziprasidone for acute management in inpatient setting}

Because we did not identify any economic evaluations for intramuscular ziprasidone, we conducted a cost analysis using data from the literature and the physician surveys. The results from the cost analysis show that using intramuscular ziprasidone for acute management in inpatient setting was associated with a total cost of $¥ 11$ 157, the lowest among all antipsychotic regimens and slightly higher than ECT (¥10 606) (table 4). Overall, hospital room and board accounted for more than $89 \%$ of the total cost. The cost of antipsychotics and ECT consisted of $1 \%-11 \%$ of the total cost. The cost of managing EPS was minimal.

While drug costs for intramuscular ziprasidone (¥1260) are higher than other antipsychotics (intramuscular haloperidol: ¥210; oral olanzapine: ¥913; oral risperidone plus lorazepam: ¥137), hospital length of stay was shorter, offsetting the higher drug costs. Compared with ECT, drug costs for intramuscular ziprasidone were higher than the costs for ECT and related procedures (¥785), and the cost for hospital room and board was similar between the two.

The results of the sensitivity analysis showed that the total cost of these regimens overlapped with each other when varying hospital length of stay using the higher and lower ends of the 95\% CI (table 5). Varying the rates of EPS based on the Zhang and colleagues study ${ }^{13}$ did not affect the results as the cost for EPS management accounted for less than $1 \%$ of the total costs.

Table 5 Sensitivity analysis of total costs by varying hospital length of stay (2017 Chinese yuan, $¥$ )

\begin{tabular}{lllccr}
\hline $\begin{array}{l}\text { Hospital length of } \\
\text { stay }\end{array}$ & $\begin{array}{l}\text { Intramuscular } \\
\text { ziprasidone }\end{array}$ & $\begin{array}{l}\text { Intramuscular } \\
\text { haloperidol }\end{array}$ & Oral olanzapine & $\begin{array}{l}\text { Oral risperidone } \\
\text { plus lorazepam }\end{array}$ & ECT \\
\hline Lower bound & 9057 & 10170 & 9193 & 8718 & 8596 \\
Higher bound & 13252 & 13656 & 14228 & 14126 & 12617 \\
\hline
\end{tabular}

ECT, electroconvulsive therapy. 


\section{DISCUSSION}

\section{Main findings}

Our analysis shows that the overall cost for the management of acute agitation was similar between intramuscular ziprasidone and other antipsychotics. The higher drug cost with intramuscular ziprasidone was offset by the lower cost of EPS management and lower cost for hospital stay. The results from our study support including intramuscular ziprasidone as an option for patients with schizophrenia from an economic standpoint. While the total cost of ECT therapy was lower than intramuscular ziprasidone, ECT is generally considered only in patients for whom antipsychotic therapy is not appropriate. ${ }^{6}$ The availability of short-acting intramuscular ziprasidone offers an additional treatment strategy for patients with schizophrenia with acute agitation who require rapid symptom control. Considering the differences in safety profiles among various antipsychotic therapies and ECT, it is beneficial for patients to have access to intramuscular ziprasidone as an option for the treatment of acute agitation in the hospital.

Consistent with findings from previous studies, ${ }^{31} 32$ our analysis shows that the costs of antipsychotics and ECT only account for a small percentage of the overall inpatient costs $(1 \%-11 \%$, depending on the therapy). The main cost drivers were hospital room and board. Based on our physician survey, the average hospital length of stay for the acute management of schizophrenia is about 29 days for intramuscular ziprasidone and ECT; higher length of stays were elicited in the survey for intramuscular haloperidol, oral olanzapine, and oral risperidone and oral benzodiazepine. The $95 \%$ CI of the length of stay estimates provided by the physicians was wide, reflecting the differences in practice in each hospital. The sensitivity analysis showed that the total cost with intramuscular ziprasidone was comparable when varying the length of stay between the higher and lower ends of the 95\% CI.

For maintenance therapy in the outpatient setting, results from the literature show that while oral ziprasidone is more expensive than oral risperidone, it is associated with a numerically higher rate of treatment response and has a more favourable tolerability profile. Compared with other atypical antipsychotics (ie, olanzapine, quetiapine and aripiprazole), oral ziprasidone is less costly and has similar efficacy.

As the American Psychological Association and the UK National Institute for Health and Care Excellence guidelines suggest, antipsychotic choice should be based on several factors, including the patient's prior experience with antipsychotic therapy on symptom control and side effects, preferred route of administration, and comorbidities. ${ }^{53}$ When compared with other atypical antipsychotics, ziprasidone has the lowest effect on weight gain, diabetes and prolactin levels, ${ }^{8} 11$ making ziprasidone a desirable option for long-term management in patients with pre-existing metabolic disorders. For those who receive oral ziprasidone as maintenance therapy and are admitted to the hospital for acute agitation, the availability of intramuscular ziprasidone allows a safe transition between oral and intramuscular treatment. For other hospitalised patients who require intramuscular treatment for acute agitation, intramuscular ziprasidone is a more tolerable alternative to intramuscular haloperidol and is particularly beneficial for patients who have a history of, or are at a high risk of, EPS. ${ }^{13}$ The risk of EPS may be higher in Chinese compared with non-Chinese Asians and Caucasian patients. ${ }^{13}$

In conclusion, it is important to make various antipsychotic agents available to patients with schizophrenia so that patients can be treated with the most appropriate therapy based on their comorbidities, past treatment experiences and preferences. Oral and intravenous ziprasidone expands the armamentarium of schizophrenia treatments. The use of ziprasidone is not cost prohibitive and may be preferred in selected populations.

\section{Strengths and Limitations}

This is the first summary of economic literature associated with ziprasidone in China and the first economic analysis asssessing the economic outcomes of intramuscular ziprasidone from the hospital's perspective in China. However, there are limitations with the study.

For the targeted literature review, Wanfang and CNKI were used to identify publications in Chinese. The Chinese Biomedicine Database was not used in our study because the database is only accessible to subscribers. Although the Chinese Biomedicine Database has limited coverage on health economics studies, there might be relevant studies that were not captured in our search.

In the cost comparison of intramuscular ziprasidone for acute management in an inpatient setting, the hospital length of stay was based on the input of nine physicians and the estimate might not represent the treatment patterns across the country. Further research based on medical record or insurance claims data from a larger, nationally representative sample is needed to validate the length of stay estimates provided by the physicians.

\section{Implications}

To our knowledge, this is the first study evaluating the economic impact of intramuscular ziprasidone for acute management of schizophrenia among hospitalised patients in China. The results from this economic analysis were complementary to the findings in the published literature assessing the economic outcomes of oral ziprasidone, which showed that oral ziprasidone was less costly and had similar efficacy compared with other atypical antipsychotics (ie, olanzapine, quetiapine and aripiprazole). In addition, although oral ziprasidone was more expensive than oral risperidone, it was associated with a numerically higher rate of treatment response and a more favourable tolerability profile.

Contributors Y-CY, XG, DL and $\mathrm{LY}$ had the idea for the article. Y-CY, FD, XG, DL and $L Y$ conducted the literature review and economic evaluation. All authors contributed to the writing of the manuscript. $\mathrm{Y}-\mathrm{CY}$ is the guarantor. 
Funding This study was funded by Pfizer Investment. DL and $L Y$ are employees of Pfizer Investment and were involved in the design and write-up of the study.

Competing interests Y-CY, FD and XG are paid consultants of Pfizer Investment. $D L$ and $L Y$ are employees of Pfizer Investment.

Patient consent for publication Not required.

Ethics approval This study used publicly available data and input from physicians that did not reveal any information at the individual subject level. Therefore, ethical review was not required. No institutional review board approval was obtained because this study did not involve human subjects.

Provenance and peer review Not commissioned; externally peer reviewed.

Data sharing statement № additional data are available.

Open access This is an open access article distributed in accordance with the Creative Commons Attribution Non Commercial (CC BY-NC 4.0) license, which permits others to distribute, remix, adapt, build upon this work non-commercially, and license their derivative works on different terms, provided the original work is properly cited and the use is non-commercial. See: http://creativecommons.org/ licenses/by-nc/4.0

\section{REFERENCES}

1. van Os J, Kapur S, van Os J. Schizophrenia. Lancet 2009;374:635-45.

2. Phillips MR, Zhang J, Shi Q, et al. Prevalence, treatment, and associated disability of mental disorders in four provinces in China during 2001-05: an epidemiological survey. Lancet 2009;373:2041-53.

3. Chong HY, Teoh SL, Wu DB, et al. Global economic burden of schizophrenia: a systematic review. Neuropsychiatr Dis Treat 2016:12:357-73.

4. Zhai J, Guo X, Chen M, et al. An investigation of economic costs of schizophrenia in two areas of China. Int $J$ Ment Health Syst 2013;7:26.

5. Lehman AF, Lieberman JA, Dixon LB. Practice guideline for the treatment of patients with schizophrenia. American Journal of Psychiatry 2004;161.

6. Guideline of Schizophrenia (second edition). Zhong Hua Yi Xue Hui Jing Shen Bing Xue Fen Hui. 2015. Available: http://guide.medlive. cn/guideline/9676 (Accessed on 25 May 2018).

7. Pike E, Leiknes KA, Wisloff T. NIPH systematic reviews: executive summaries. Efficacy and safety of first-generation and secondgeneration anti-psychotic drugs for schizophrenia in adults: an overview of systematic reviews. Oslo, Norway: Knowledge Centre for the Health Services at The Norwegian Institute of Public Health, 2009.

8. Leucht S, Cipriani A, Spineli L, et al. Comparative efficacy and tolerability of 15 antipsychotic drugs in schizophrenia: a multipletreatments meta-analysis. Lancet 2013;382:951-62.

9. Buchanan RW, Kreyenbuhl J, Kelly DL, et al. The 2009 schizophrenia PORT psychopharmacological treatment recommendations and summary statements. Schizophr Bull 2010;36:71-93.

10. Mclntyre RS. Managing weight gain in patients with severe mental illness. J Clin Psychiatry 2009;70:e23.

11. Bai Z, Wang G, Cai S, et al. Efficacy, acceptability and tolerability of 8 atypical antipsychotics in Chinese patients with acute schizophrenia: A network meta-analysis. Schizophr Res 2017;185:73-9.

12. Currier GW, Medori R. Orally versus intramuscularly administered antipsychotic drugs in psychiatric emergencies. J Psychiatr Pract 2006;12:30-40.
13. Zhang $\mathrm{H}$, Wang $\mathrm{G}$, Zhao J, et al. Intramuscular ziprasidone versus haloperidol for managing agitation in Chinese patients with schizophrenia. J Clin Psychopharmacol 2013;33:178-85.

14. Yu X, Correll CU, Xiang YT, et al. Efficacy of Atypical Antipsychotics in the Management of Acute Agitation and Aggression in Hospitalized Patients with Schizophrenia or Bipolar Disorder: Results from a Systematic Review. Shanghai Arch Psychiatry 2016;28:241.

15. Integrated Management Platform of Beijing Medicine Sunshine Purchase. 2018. Available: http://210.73.89.76/ServiceSelect/ GetServiceSelectList (Accessed on 25 May 2018).

16. YAOZH Net (Internet). 2018. Available: https://www.yaozh.com/ (Accessed on 25 May 2018).

17. Medical Service Items and Price List. Beijing Municipal Commission of Development and Reform [Internet]. 2018. Available: http:// service2.bjpc.gov.cn/bjpc/mediprice/medical_price_table.jsp (Accessed on 25 May 2018).

18. XUXF, YuFH, Wang J. Analyzing the hospitalization expense and management status of severe mental illness. Zhongguo Wei Shen Jing Ji 2013;32:53-6.

19. Guan X, Liu Q, Tang WX. Cost-effectiveness analysis of five common atypical antipsychotics for first-episode schizophrenia in China based on decision-tree model. Zhongguo Xin Yao Za Zhi 2017;26:2101-6.

20. Du B. Evidence-based pharmacoeconomic evaluation of ziprasidone and risperidone in the treatment of schizophrenia. Hua Xi Yao Xue Za Zhi 2010;25:502-3.

21. He CC. Ziprasidone and fumarate sulfur Krishna flat improve patients with schizophrenia, social function of economic evaluation. Zhongguo Yi Yao Zhi Nan 2012;10:36-7.

22. Hao SX, Liu WJ. Ziprasidone versus Risperidone in the Treatment of Schizophrenia: Cost-effectiveness Analysis. Shanxi Yi Yao Za Zhi 2015;44:2944-5.

23. Shuai HL. Ziprasidone versus risperidone in the treatment of schizophrenia: cost-effectiveness analysis. Zhongguo Yi Yuan Yong Yao Ping Jia Fen Xi 2008;8:289-90.

24. Duan JF. Pharmacoeconomic analysis of two drugs for schizophrenia. Shanxi Yi Yao Za Zhi 2016;45:1459-60.

25. Wang $Y Q, X Y H, W G X$. Efficacy and economic evaluation of three anti-schizophrenic drugs. Shandong Da Xue Xue Bao 2014;52(Z2):196-7.

26. Liu QH. Pharmacoeconomic analysis of four commonly used antipsychotics for schizophrenia. Zhongguo Tang Dai Yi Yao 2011;18:182-201.

27. Wang RC, Yang B, Cao XL. Cost-result analysis of fluvoxamine and chlorimipramine in treatment of obsessive and compulsive disorder. Heilongjiang Yi Yao Ke Xue 2010;33:72-3.

28. Wei CW. Economic analysis of two drugs for schizophrenia. Ya Tai Chuan Tong Yi Yao 2011;7:185-6.

29. Han P, Zhou DS, Wao FQ. Pharmacoeconomic analysis of nonclassical antipsychotic drugs commonly used for schizophrenia. Zhongguo Xian Dai Yi Shen 2011;49:118-20.

30. Lin ZY, Yang X, FQ L. Health economic impact of ziprasidone and clozapine in the treatment of refractory schizophrenia. Lin Chuang Jing Shen Yi Xue Za Zhi 2009;19:97-8.

31. Liu P, Chen DG. Investigation and analysis of hospitalization expenses of schizophrenics in Jiangbei District of Chongqing from 2005 to 2014. Chongqing Yi Xue 2016;45:2252-4.

32. Wang BJ, XP L. Analysis of factors influencing hospitalization expenses of 5439 psychiatric inpatients. Zhongguo Yi Yuan Tong Ji 2013:1:30-6.

33. NICE. Psychosis and schizophrenia in adults: prevention and management (2014). National Institute for Clinical Excellence (NICE) Guidelines [CG178]. 2014. Available: https://www.nice.org.uk/ guidance/cg178 (Accessed on 25 May 2018). 


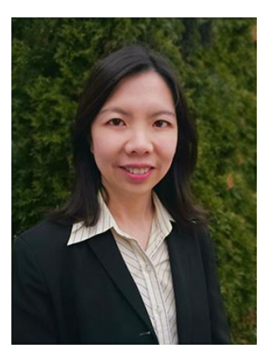

Yu-Chen Yeh, MS, RPh is a Director in Health Economic and Outcomes Research at Pharmerit

International. Yu-Chen has more than 15 years of experience in health economics and outcomes research. Her experience includes economic analyses from payer's and hospital's perspectives, chart review studies, claims database analyses, global value dossiers, and outcomes research strategic planning. Prior to joining Pharmerit International, Yu-Chen worked in the Center for Drug Policy at the Partners Healthcare, a large healthcare system in the greater Boston area in the United States, where she provided input for hospital formulary decision making, developed drug prescribing guidelines, conducted medication utilization reviews, and developed pharmacy budget forecast models for new drugs. Yu-Chen Yeh holds a MS in Pharmaceutical Outcomes and Policy from the University of North Carolina at Chapel Hill and a BS Pharmacy from the National Taiwan University. She is a licensed pharmacist in the United States. 